\title{
AN INTRODUCTION TO HEALTHY AND SUSTAINABLE FOOD SYSTEMS
}

\author{
Mark Lawrence and Sharon Friel
}

Humanity is facing an existential threat as the impacts of its activities exceed planetary boundaries. Modern industrialised food systems are major contributors to this threat through their profligate use of finite resources, including land, energy and freshwater (Steffen et al., 2015) and degradative impacts on the environment, including greenhouse gas emissions (Vermeulen, Campbell, \& Ingram, 2012), biodiversity loss (FAO, 2019) and food waste (FAO, 2011). In turn, these environmental harms are affecting food yields, quality and safety as well as the macro- and micro-nutrient composition of certain staple foods (Ebi, CampbellLendrum, \& Wyns, 2018).

Modern industrialised food systems are also associated with poor public health outcomes. Dietary risk factors are leading contributors to the global burden of disease (Afshin et al., 2019). In particular, dietary imbalances are associated with a number of non-communicable diseases (NCDs), such as cardiovascular disease, and certain cancers and diabetes and dietary excesses are associated with nearly 2 billion adults being overweight or obese (Afshin et al., 2019). At the same time, dietary inadequacies are contributing to 2 billion people suffering from micronutrient deficiencies (FAO, IFAD, UNICEF, WFP, \& WHO, 2018) and 821 million people being undernourished. It is estimated that malnutrition in all its forms costs the global economy up to US\$3.5 trillion each year (World Health Organization, 2016).

Healthy and sustainable food systems are prerequisites for human existence. They must provide a sufficient amount, quality and variety of nutritious food while discouraging the proliferation of junk food (ultra-processed food or nutritionally poor, resource-wasteful food) to meet the nutritional and socio-cultural needs of populations now and into the future. To do this, food systems must function in ways that do not undermine the Earth's capacity to provide life-sustaining resources (Niles et al., 2017). However, current food systems are broken (Branca et al., 2019) and their contributions to poor public health outcomes and environmental harms are not only substantial in absolute terms but also inequitable, with those who have contributed minimally to the problems often being most affected and least able to respond (Friel, 2019).

In this book; we adopt the UN's High Level Panel of Experts on Food Security and Nutrition's definition of a food system as being an entity that "gathers all the elements (environment, 


\section{T\&F PROOFS NOT FOR DISTRIBUTION}

2 Mark Lawrence and Sharon Friel

people, inputs, processes, infrastructures, institutions, etc.) and activities that relate to the production, processing, distribution, preparation and consumption of food and the outputs of these activities, including socio-economic and environmental outcomes" (HLPE, 2014). And a sustainable food system is one that "delivers food security and nutrition for all in such a way that the economic, social and environmental bases to generate food security and nutrition for future generations are not compromised" (HLPE, 2014). Health is implicit in this food system definition through its reference to delivering food security and nutrition outcomes.

The evolution of modern humans began about 2.5 million years ago (Harari, 2015), and over approximately 100,000 generations since that time humans have survived, thrived and evolved, all the while being nurtured by food systems of various forms. Though the health and sustainability qualities of those food systems have varied over time and by place, it is self-evident they have persisted sufficiently to support the endurance of humans to the present time and across the globe. Today, it is multiple interrelated social, economic, demographic, political and technological developments that are rendering relationships between food systems and human existence untenable. Fundamentally, the extent and pace of these developments clash with two immutable realities: the physical limits of the planet's environmental boundaries (Steffen et al., 2015); and the nutritional requirements of the human body, which have evolved over millions of years (Eaton, Eaton III, Konner, \& Shostak, 1996). Unless significant and prompt action is taken, the adverse impacts resulting from the gap between policy and human behaviour practices and fixed realities are destined to be exacerbated as the global population approaches an estimated 10 billion people by 2050 (UN DESA, 2017).

After approximately 100,000 generations of human existence, whether there will be sufficient, nutritious, safe and affordable food to continue to nurture humanity into the future will be determined by the actions of our generation.

\section{Global policies and actions to promote healthy and sustainable food systems}

The body of evidence associated with the challenges to healthy and sustainable food systems is growing rapidly. Consequently, the agenda has begun to receive significant policy attention from $\mathrm{UN}$, national, and local government agencies as well as from researchers, practitioners, civil society and the private sector. Notable global policy developments in recent times have been:

1. 2014: The Second International Conference on Nutrition's Rome Declaration on Nutrition: the ICN2, co-organized by the Food and Agriculture Organization of the United Nations (FAO) and the World Health Organization (WHO), held in Rome, in November 2014, adopted the Rome Declaration on Nutrition and its companion Framework for Action (FAO \& WHO, 2015). The Framework for Action sets out 60 voluntary recommendations for policies and actions necessary to achieve the objectives of ending all forms of malnutrition and providing sustainable food systems delivering healthy diets to all. Subsequently, the Framework has been supported with a follow-up resource guide for countries, based on the policy recommendations of the ICN2 and entitled, Strengthening Nutrition Action (FAO \& WHO, 2018).

2. 2015: The UN Agenda for Sustainable Development and Sustainable Development Goals: In September 2015, world leaders adopted the 2030 Agenda for Sustainable Development and its associated Sustainable Development Goals (SDGs) at the UN 


\section{T\&F PROOFS NOT FOR DISTRIBUTION}

Introduction 3

General Assembly. The SDGs set out a roadmap for achieving equitable development and global prosperity by 2030. Most of the goals and targets directly or indirectly impact nutrition and, conversely, investing in and acting on food systems will help achieve the SDGs. Of particular relevance to this book is SDG12, "Sustainable consumption and production", being implemented through the Sustainable Food Systems Programme of the One Planet Network which itself is implementing the 10-year Framework of programmes on sustainable consumption and production (UN DESA, 2014).

3. 2016: The UN Decade of Action on Nutrition (2016-2025): In April 2016, the UN General Assembly proclaimed the period from 2016 to 2025 the UN Decade of Action on Nutrition (UN, 2016) with the UN Resolution on the UN Decade of Action on Nutrition. The aim of the Decade of Action on Nutrition is to have countries and their partners commit to and act on nutrition objectives: (a) to implement the ICN2 commitments; (b) to achieve the Global Nutrition and dietrelated NCD targets by 2025 (WHO, 2010; 2014); and (c) to achieve the SDGs by 2030. The Decade of Action on Nutrition activities are centred on six cross-cutting Action Areas that are used to cluster the 60 ICN2 Framework for Action recommendations. The first of these Action Areas is "Sustainable, resilient food systems for healthy diets" (FAO \& WHO, 2018).

4. 2019: The EAT-Lancet Commission report on healthy diets from sustainable food systems, and the Lal cet Commission report on the Global Syndemic of Obesity, Undernutrition, and Climate Cnange: In 2019, two landmark Lancet Commission reports were published, each including analyses of the causes of and solutions to topics related to healthy and sustainable food systems. First, the EAT-Lancet report on healthy diets from sustainable food systems (Willett et al., 2019) proposes dietary modelling-informed targets for healthy diets and sustainable food systems that are designed to help achieve the SDGs and the Paris Climate Agreement and to be universal for all food cultures and production systems. The report recommends that to feed 10 billion people in 2050, dietary patterns typically should consist of a diverse range of plantbased foods, low amounts of animal-based foods, unsaturated fats, and small amounts of refined grains, processed foods and added sugars, in amounts appropriate for a healthy weight (Willett et al., 2019).Second, the Report of the Lancet Commission on Obesity demonstrates that the pandemics of obesity, undernutrition, and climate change represent the paramount challenge for humans, the environment and our planet (Swinburn et al., 2019). These interacting pandemics represent the Global Syndemic with common, underlying drivers in the food, transport, urban design, and land use systems. The Lancet report proposes nine recommendations to mitigate these three pandemics simultaneously.

5. 2019: Climate Change and Land: an IPCC special report on climate change, desertification, land degradation, sustainable land management, food security, and greenhouse gas fluxes in terrestrial ecosystems: In August 2019, the Intergovernmental Panel on Climate Change released its Special Report on Climate Change and Land (IPCC, 2019). Its chapter on food security uses a food systems approach to examine how climate change affects food and nutrition security. This comprehensive chapter addresses the supply-side and demand-side options available for food systems to adapt and mitigate and the synergies and trade-offs associated with these options 


\section{T\&F PROOFS NOT FOR DISTRIBUTION}

4 Mark Lawrence and Sharon Friel

\section{Why healthy and sustainable food systems?}

There is no one universal cause of, nor one silver bullet solution to, the food-related public health and environmental sustainability problems confronting humankind. Instead the formulation of effective and safe policy and action responses to these problems faces multiple challenges. First, there is the challenge of the complexity and sheer size of these problems involving multiple drivers, actors and places. Second, there is the challenge that among these drivers, actors and places, there are multiple dynamic nonlinear interactions. Third, can play a significant role in shaping the nature and scope of the problem and potential solution. For instance, although consensus is emerging around the characteristics of a healthy and sustainable diet, the generalisability of the dietary advice is conditional on many contextual factors that affect how foods are produced, processed, distributed and consumed in different places around the world. Fourth, food's integral role in economies means that politics, particularly involving actors whose interests align with maintaining the status quo, is inevitable in formulating policy activities to transform food systems (Lawrence, Friel, Wingrove, James, \& Candy, 2015).

These challenges highlight why a healthy and sustainable food systems perspective provides a fit-for-purpose approach to analysing causes and identifying solutions to the problems. A systems perspective provides the means to see all drivers, actors, places, contexts and circumstances (as well as all their inter-relationships) associated with food supply and food demand as a whole rather than thinking of them operating in isolation from each other. Systems thinking enables analysis of multiple dynamic non-linear interactions among those factors affecting food-related problems and to identify how and where to intervene effectively, taking into account potential trade-offs, to tackle those problems (Peters, 2014). Also there are synergies to be leveraged and co-benefits to be gained from such food systems' interventions because they can contribute simultaneously to health and sustainability outcomes (Tirado, 2015; Global Panel on Agriculture and Food Systems for Nutrition, 2016; Niles et al., 2018; Parsons \& Hawkes, 2018).

Figure 0.1 provides a conceptual framework for thinking about the structure and operation of a food system. The framework sets out an overarching coherent perspective to the system's multiple structural components that at its core extend across food supply chains, food environments and consumer behaviour and how these lead to diets and ultimately nutrition and health outcomes and social, economic and environmental impacts. These structural components are themselves underpinned by political, programme and institutional actions that also are linked to the SDGs. And overlaying the core structural components are the following drivers:

- biophysical and environmental;

- innovation, technology and infrastructure;

- political and economic;

- socio-cultural; and demographic.

The framework also illustrates the intricate operations of the system in terms of the many inputs and outputs and multiple relationships among its structural components. Critically, those relationships are not simply a series of linear connections between system 


\section{T\&F PROOFS NOT FOR DISTRIBUTION}

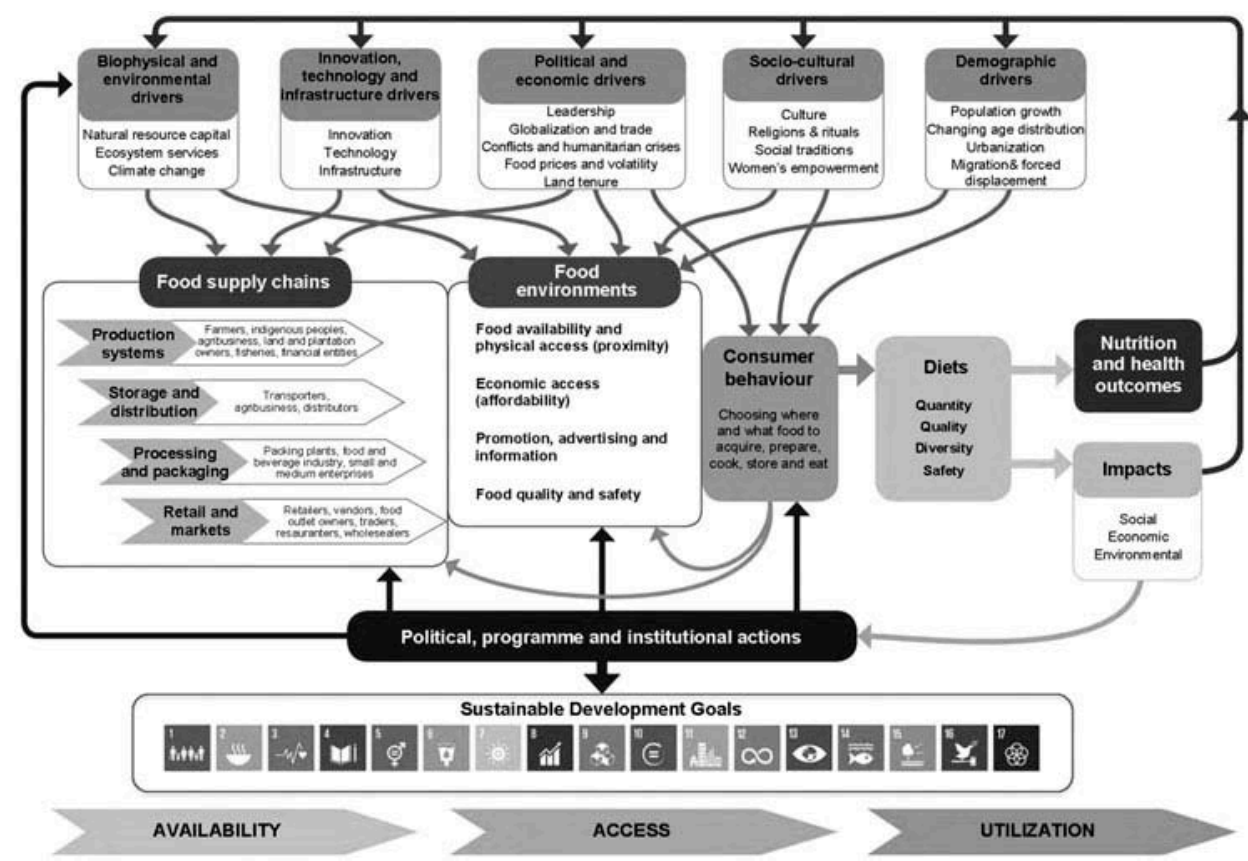

FIGURE 0.1 Conceptual framework of the structure and operation of a food system Source: FAO (2017).

components. Instead the relationships are characterised by multiple interactions among component parts and so are continuously changing and influencing one another through non-linear pathways and feedback mechanisms. It is for this reasen that any attempt to understand a system simply by looking at its individual parts is limited because rarely operate in isolation of other parts and instead there is a need to think of the whole as being greater than the sum of its individual parts.

The framework presented in Figure 0.1 not only helps us understand the structure and operation of a food system, but also it serves as a heuristic device for strategically planning and evaluating policies and actions designed to promote healthy and sustainable food systems. It can help us analyse the underlying causes of a problem, and in certain instances the "cause of the cause" of a problem, and therefore identify where to intervene in the system and predict the consequences of that intervention throughout the system. For instance, overconsumption of junk food is both a health and sustainability problem. The immediate cause of that problem is located in the consumer behaviour component of the system and therefore the immediate solution is to intervene to change consumer behaviour. However, how accurate is that analysis and how effective is the proposed solution? When viewed from a food systems perspective, the antecedents of this behaviour might be located at several other points within the system. Is junk food more affordable, accessible and/or available than a more nutritious alternative? How and why is this happening? Does the cost of junk food reflect the true health or environmental cost of that food or are such costs externalised? If locally sourced nutritious foods were to replace junk foods, might there be additional benefits, such as supporting local food economies and cultures? 


\section{T\&F PROOFS NOT FOR DISTRIBUTION}

6 Mark Lawrence and Sharon Friel

\section{What this book contributes}

In their extensive critical analysis of food systems research, Bene et al. (2019) identify four prominent narratives of food system problems and corresponding solutions: (1) the inability of the system to feed the future world population; (2) the inability of the system to deliver a healthy diet; (3) the inability of the system to produce equal and equitable benefits; and (4) the unsustainability of the system and its impact on the environment. The aim of this book is to provide an up-to-date research-based reference text that draws these four narratives together by focusing on healthy and sustainable food systems at three levels:

1. To describe what healthy and sustainable food systems are and why they are important.

2. To critically analyse how and why health, environmental sustainability and equity problems have arisen via the food system.

3. To identify the political, public policy, industry, civil society and consumer actions that can be taken to ensure sustainable food systems that achieve healthy and sustainable food systems that deliver healthy diets to all.

The topics covered in the book are priorities for a healthy and sustainable food systems agenda. The book brings together a wide range of contributors who are international experts in their field. Their experience is derived from a plurality of disciplines, countries and topic areas, thereby providing rich research, practice and contextual insights. The approach taken in the book is innovative in two key ways: (1) it links health, environmental sustainability and equity dimensions; and (2) it challenges the dominance of a "reductionist" (nutrient) worldview, i.e. a focus on changing people's consumption of certain nutrients as a means to tackle nutrition problems, that pervades much nutrition policy discourse and reorients to foods, diets and food systems as a basis to inform nutrition policy activities.

\section{The structure of the book}

The book is divided into four integrated Parts. Each Part consists of chapters based on an evidence-informed approach to the topic by drawing on recent authoritative global reports and/or peer-reviewed literature.

Part I, "Overarching dimensions of healthy and sustainable food systems", explains the nature and scope of the challenges confronting food systems. It consists of three chapters that set out the core topics for the overall themes of the book, written by leading international experts in each of these topics:

1. Health: Based on the findings of the latest Global Nutrition Report and prepared by the co-editors of the Report (Chapter 1).

2. Sustainability: Prepared by the Chair of the International Union of Nutritional Sciences Task Force on Sustainable Diets (Chapter 2).

3. Equity: Led by a member of the Project Team for the Nutrition and Food Systems Report of the UN's High Level Panel of Experts/Committee on World Food Security (Chapter 3).

Part II, "The food system", identifies the components, the actors and the inter-relationships within food systems. This Part starts with a scene-setting chapter that provides an overview of 


\section{T\&F PROOFS NOT FOR DISTRIBUTION}

Introduction

different concepts and models for food systems as a coherent whole (Chapter 4). Then each of the remaining five chapters provides an in-depth analysis of one of the following food system components: food production (Chapter 5); food manufacturing (Chapter 6); food retail and distribution (Chapter 7); the food services sector (Chapter 8); and food consumption (Chapter 9). We are aware of the potential contradiction of organising Part II as a linear sequence of the constituent parts of the food system when otherwise we emphasise the importance of thinking about food systems as joined-up entities in which the whole is more than the sum of its parts. However, organising as separate chapters affords the opportunity to undertake a detailed examination of the parts and the integration is addressed in this chapter and the Conclusion, as well as the dedicated chapter on food systems as a whole at the start of this Part (Chapter 4).

Part III, "Healthy and sustainable diets", analyses the characteristics of a healthy and sustainable diet. The Part starts with a scene-setting chapter (Chapter 10) that provides an overview of what a healthy and sustainable diet should be. Then each of the remaining four chapters provides an indepth analysis of one of the following commonly identified challenges to a healthy and sustainable diet: overconsumption (Chapter 11); excessive animal product consumption (Chapter 12); excessive junk food consumption (Chapter 13); and food waste (Chapter 14).

Part IV, "Creating healthy and sustainable food systems: politics, policy, people and practitioners", examines political, policy, people and practitioner activities to help transform the current food system into a healthy and sustainable food system. Despite much knowledge about the problem and awareness of the need for transformation, there is general inertia regarding meaningful action by policy-makers and behaviour change by the population. The Part commences with a chapter that frames the food system from a political economy perspective that explains why planning for change needs to extend beyond changes to the health sector to other sectors, such as agriculture, other systems, such as the economic system, and other actors, such as philanthropists (Chapter 15). Then each of the remaining three chapters provides an in-depth analysis of how change can be achieved in one of the following settings: policy actions (Chapter 16), people's practices (Chapter 17); and practitioners' advocacy (Chapter 18).

The Conclusion provides a discussion of the main issues raised throughout the book, the lessons learned and a view to the future for promoting healthy and sustainable food systems.

\section{References}

Afshin, A., Sur, P. J., Fay, K. A., Cornaby, L., Ferrara, G., Salama, J. S., ... Murray, C. J. L. (2019). Health effects of dietary risks in 195 countries, 1990-2017: A systematic analysis for the Global Burden of Disease Study 2017. The Lancet. doi:10.1016/S0140-6736(19)30041-8.

Branca, F., Lartey, A., Oenema, S., Aguayo, V., Stordalen, G. A., Richardson, R., ... Afshin, A. (2019). Transforming the food system to fight non-communicable diseases. BMJ, 364, 1296. doi:10.1136/bmj.1296.

Eaton, S. B., EatonIII, S. B., Konner, M. J., \& Shostak, M. (1996). An evolutionary perspective enhances understanding of human nutritional requirements. Journal of Nutrition, 126, 1732-1740.

Ebi, K., Campbell-Lendrum, D., \& Wyns, A. (2018). The 1.5 health report: Synthesis on health and climate science in the IPCC SR1.5. Available at: www.who.int/globalchange/181008_the_1_5_healthreport.pdf FAO. (2011). Global food losses and food waste: Extent, causes and prevention. Rome: FAO.

FAO (2017). Nutrition and food systems: A report by the High Level Panel of Experts on Food Security and Nutrition of the Committee on World Food Security. Rome: FAO. Available at: www.fao.org/3/a-i7846e.pdf

FAO. (2019). The state of the world's biodiversity for food and agriculture. Available at: www.fao.org/ 3/CA3129EN/CA3129EN.pdf 


\section{T\&F PROOFS NOT FOR DISTRIBUTION}

8 Mark Lawrence and Sharon Friel

FAO, IFAD, UNICEF, WFP, \& WHO. (2018). The state of food security and nutrition in the world 2018: Building climate resilience for food security and nutrition. Available at: www.fao.org/3/ I9553EN/i9553en.pdf

FAO \& WHO. (2015). Second International Conference on Nutrition: Report of the Joint FAO/ WHO Secretariat on the Conference. Available at: www.who.int/nutrition/topics/WHO_FAO_a nnounce_ICN2/en/index $2 . h t m l$

FAO \& WHO. (2018). Strengthening nutrition action: A resource guide for countries based on the policy recommendations of the Second International Conference on Nutrition (ICN2). Available at: www.who.int/nutrition/publications/strengthening-nutrition-action/en

Friel, S. (2019). Climate change and the people's health. New York:Oxford University Press.

Global Panel on Agriculture and Food Systems for Nutrition. (2016). Food systems and diets: Facing the challenges of the 21st century. Available at: www.glopan.org

Harari, Y. N. (2015). Sapiens: A brief history of humankind. New York: Harper.

HLPE. (2014). Food losses and waste in the context of sustainable food systems. Rome: HLPE.

IPCC. (2019). Climate change and land. Available at: www.ipcc.ch/report/srccl

Lawrence, M. A., Friel, S., Wingrove, K., James, S. W., \& Candy, S. (2015). Formulating policy activities to promote healthy and sustainable diets. Public Health Nutrition, 18(13): 2333-2340.

Niles, M. T., Ahuja, R., Barker, T., Esquivel, J., Gutterman, S. ... Vermeulen, S. (2018). Climate change mitigation beyond agriculture: A review of food system opportunities and implications. Renewable Agriculture and Food Systems, 33(3): 297-308. doi:10.1017/S1742170518000029.

Niles, M. T., Ahuja, R., Esquivel, M., Mango, N., Duncan, M., Heller, M., \& Tirado, C. (2017). Climate change and food systems: Assessing impacts and opportunities. Washington, DC: Meridian Institute. Parsons, K. \& Hawkes, C. (2018). Connecting food systems for co-benefits: How can food systems combine diet-related health with environmental and economic policy goals?Copenhagen, Denmark: WHO.

Peters, D. H. (2014). The application of systems thinking in health: Why use systems thinking? Health Research Policy and Systems, 12(1), 51. doi:10.1186/1478-4505-12-51.

Steffen, W., Richardson, K., Rockström, J., Cornell, S. E., Fetzer, I., Bennett, E. M., .. Sörlin, S. (2015). Planetary boundaries: Guiding human development on a changing planet. Science, 347(6223), 1259855. doi:10.1126/science.1259855 \% Science.

Swinburn, B. A., Kraak, V. I., Allender, S., Atkins, V. J., Baker, P. I., Bogard, J. R., ... Devarajan, R. (2019). The global syndemic of obesity, undernutrition, and climate change: The Lancet Commission report. The Lancet, doi:10.1016/S0140-6736(18)32822-32828.

Tirado, C. (2015). Sustainable food systems and health: The convenient truth of addressing climate change while promoting health. Available at: www.unscn.org/files/Announcements/EXE_2_Susta inable_Food_systems_and_health.pdf

UN (United Nations). (2016). Decade of action on nutrition. Available at: www.who.int/nutrition/ GA_decade_action/en/

UN DESA. (2014). The 10-Year Framework of Programmes on sustainable consumption and production patterns (10YFP). Available at: https://sustainabledevelopment.un.org/content/documents/ 1444HLPF_10YFP2.pdf

UN DESA. (2017). World population prospects 2017. Available at: https://population.un.org/wpp/

Vermeulen, S. J., Campbell, B. M., \& Ingram, J. S. I. (2012). Climate change and food systems. Annual Review of Environment and Resources, 37(1), 195-222. doi:10.1146/annurev-environ-020411-130608.

WHO-(World Health-Organization). (2010). Diet-related voluntary global NCD targets. Available at: www.who.int/nmh/ncd-tools/definition-targets/en/

WHO. (2014). Global nutrition targets 2025. Available at: www.who.int/nutrition/global-target-2025/en/

WHO. (2016). Malnutrition in the crosshairs. Available at: www.who.int/nutrition/pressrelease-FAO WHO-symposium-malnutrition/en/

Willett, W., Rockström, J., Loken, B., Springmann, M., Lang, T., Vermeulen, S., ... Murray, C. J. L. (2019). Food in the Anthropocene: The EAT-Lancet Commission on healthy diets from sustainable food systems. The Lancet. doi:10.1016/S0140-6736(18)31788-31784. 